around the tumour. We were unable to observe the effect of withdrawal of HBOT because corticosteroid treatment was introduced as soon as the mass lesion became apparent; however, improvement was maintained between daily treatments. Two forms of cerebral oedema are described. ${ }^{3}$ Vasogenic cerebral oedema is due to a change in capillary permeability and can occur around mass lesions. Cytotoxic cerebral oedema is secondary to cellular damage, usually hypoxia. Corticosteroids can reduce vasogenic oedema but are not thought to be of value in cytotoxic oedema. HBOT may reduce oedema by causing cerebral vasoconstriction ${ }^{4}$ and has been shown to reduce intracranial pressure. ${ }^{5}$ After carbon

\section{Covert tamponade}

\author{
Mark G Jenkins, David Cochrane
}

Cardiac tamponade is a very uncommon complication of open cardiac surgery, whereas pericardial effusion is common. ${ }^{12}$ Studies put the incidence of effusion at $64 \%$ and tamponade at $0.4-1.9 \% .^{12}$

A 58 year old man presented to the accident and emergency department with a sudden onset of fatigue and sweatiness. $\mathrm{He}$ had had aortic valve replacement three weeks earlier and was a known non-insulin dependent diabetic. On examination he was pale and clammy. His blood pressure was $115 / 70 \mathrm{~mm}$ $\mathrm{Hg}$, pulse 100 with heart sounds I+II+ prosthetic S2 clearly audible. On detailed examination his femoral pulses were not palpable on inspiration (pulsus paradoxus).

A portable ultrasound machine in the department (Shimasonic SDL-30) was used to visualise the heart. This identified fluid within the pericardial sac. Chest radiography showed an enlarged heart (fig 1). Formal echocardiography showed $2.65 \mathrm{~cm}$ of fluid posterior to the heart causing tamponade (fig 2 ). He was taken to cardiac theatre where $50 \mathrm{ml}$ of serous fluid was aspirated with dramatic clinical improvement. A further $510 \mathrm{ml}$ was drained subsequently. He made an uneventful recovery.

Late tamponade presents diagnostic difficulty as clinical features are vague and atypical. ${ }^{3}$ The classical Beck's triad, distended neck veins, hypotension and muffled heart sounds, is not always present. Diagnosis is made rapidly with echocardiography. ${ }^{3}$

1 Pepi M, Muratori M, Barbier P, et al. Pericardial effusion after cardiac surgery: incidence, site, size and haemodynamic consequences. Br Heart $\mathcal{F}$ 1994;72:327-31.

2 Yilmaz AT, Arslan M, Demirklic U, et al. Late posterior cardiac tamponade after open heart surgery. $\mathcal{f}$ Cardiovasc Surg 1996;37:615-20. monoxide poisoning any patient left with neurological sequelae should be considered for brain imaging to exclude coexistent pathology.

1 Norkool DM, Kirkpatrick JN. Treatment of acute carbon monoxide poisoning with hyperbaric oxygen: a review of 115 cases. Ann Emerg Med 1985;14:1 168-71.

2 Goldbaum LR, Orellano T, Dergal E. Mechanism of the toxic action of carbon monoxide. Ann Clin Lab Sci 1976;6: 372-6.

3 Mendelow AD. Raised intracranial pressure, cerebral oedema, hydrocephalus and intracranial tumours. In: Walton J, ed. Brain's diseases of the nervous system. 10th Ed. Oxford: Oxford University Press, 1993: 146.

4 Hammarlund C. The physiologic effects of hyperbaric oxygen. In: Kindwall EP, ed. Hyperbaric medicine practice. Flagstaff, Arizona: Best Publishing Company, 1994: 20.

5 Lample LA, Frey G. Hyperbaric oxygen in intracranial abscess. In: Kindwall EP, ed Hyperbaric medicine practice. Flagstaff, Arizona: Best Publishing Company, 1994: 664.

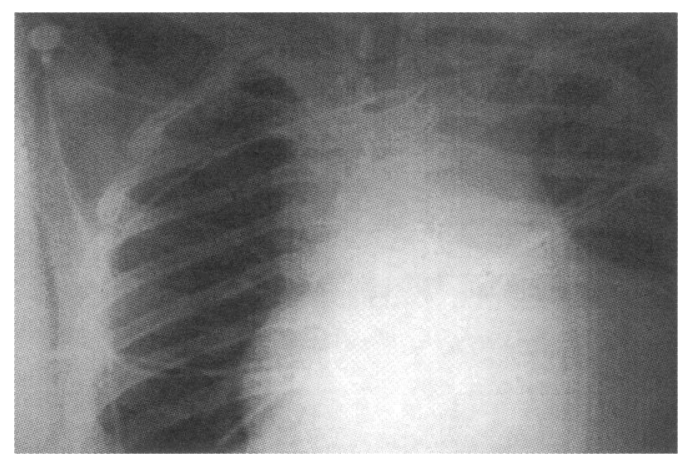

Figure 1 Chest radiograph showing enlarged cardiac shadow.

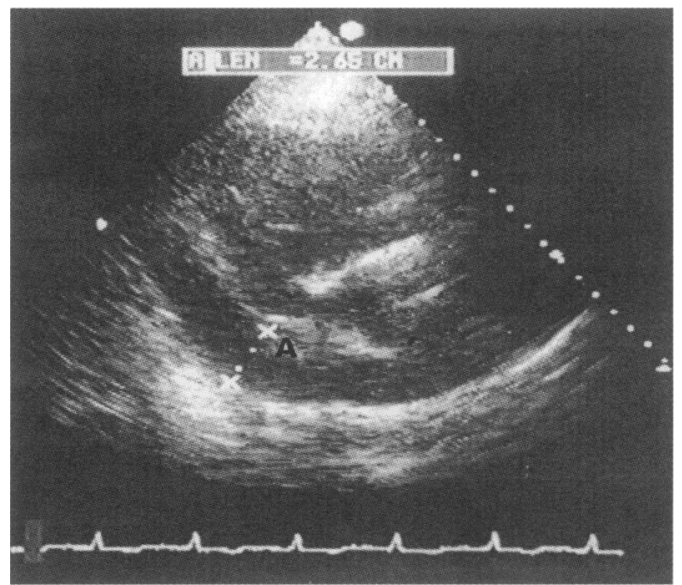

Figure 2 Echocardiography showing fluid $(A)$ in the posterior aspect of the pericardial sac.

3 Chuttani K, Tischler MD, Pandian NG, et al. Diagnosis of cardiac tamponade after cardiac surgery: relative value of clinical, echocardiographic and haemodynamic signs. $\mathrm{Am}$ clinical, echocardiographic and ha 